\title{
Wetting collapse in opencast coalmine backfill
}

\section{R. Blanchfield and W. F. Anderson}

\section{J. A. Charles and H. D. Skinner, Building Research Establishment Ltd}

Wetting collapse can be a major hazard where building developments are located on opencast backfill and Blanchfield and Anderson have focused attention on some of the significant parameters controlling the magnitude of the potential for collapse compression in such fills. They have also identified the need for a much better understanding of creep behaviour.

On the basis of a series of laboratory tests, the authors conclude that, up to $700 \mathrm{kPa}$ overburden stress, inundation volume change in opencast coalmine mudstone backfill is related to the overburden stress level, and for predictive purposes a linear fit can be put to the data (paragraph 46). It is further claimed (paragraph 23) that the linear relationship in Fig. 5 of their paper, which shows wetting collapse compression increasing from zero at $40 \mathrm{kPa}$ to about $13 \%$ at $700 \mathrm{kPa}$, refutes the findings of other investigations described in References 2-6. These references include the field investigations carried out by BRE at the Horsley site in Northumberland ${ }^{4}$ and the comprehensive review of field data from British Coal opencast sites carried out by Scott Wilson. ${ }^{5}$

At the Horsley opencast site, the fill was principally mudstone and sandstone and had not been systematically compacted during backfilling. Settlement at different depths within the fill was monitored using magnet extensometers. The groundwater level was monitored using standpipe piezometers. The instrumentation made it possible to measure the vertical compression at different depths below ground level and to relate the compression to the rising groundwater level. Fig. 13 shows the vertical compressions monitored over a three-year period between April 1974 and April 1977 as the groundwater level rose some $34 \mathrm{~m}$ at a location where the fill was $63 \mathrm{~m}$ deep. The groundwater had risen to within $19 \mathrm{~m}$ of ground level by April 1977. The data are plotted as wetting compression against overburden stress prior to the rise in groundwater level. There is considerable scatter in the results, but there is no indication of an increase in wetting compression with increasing overburden stress.

Compression continued to be monitored after the groundwater level stabilised. Fig. 14 shows the total vertical compression over a 20-year period plotted against the overburden stress prior to the rise in groundwater level. Not all the vertical compression shown in Fig. 14 is attributable to wetting collapse. Below the level to which the water table rose, there will be some creep compression subsequent to the rise in groundwater level. Above the level to which the water table rose, the compression will be partly attributable to creep and partly to wetting caused by the downward migration of surface water. However, it is likely that at all depths most of the
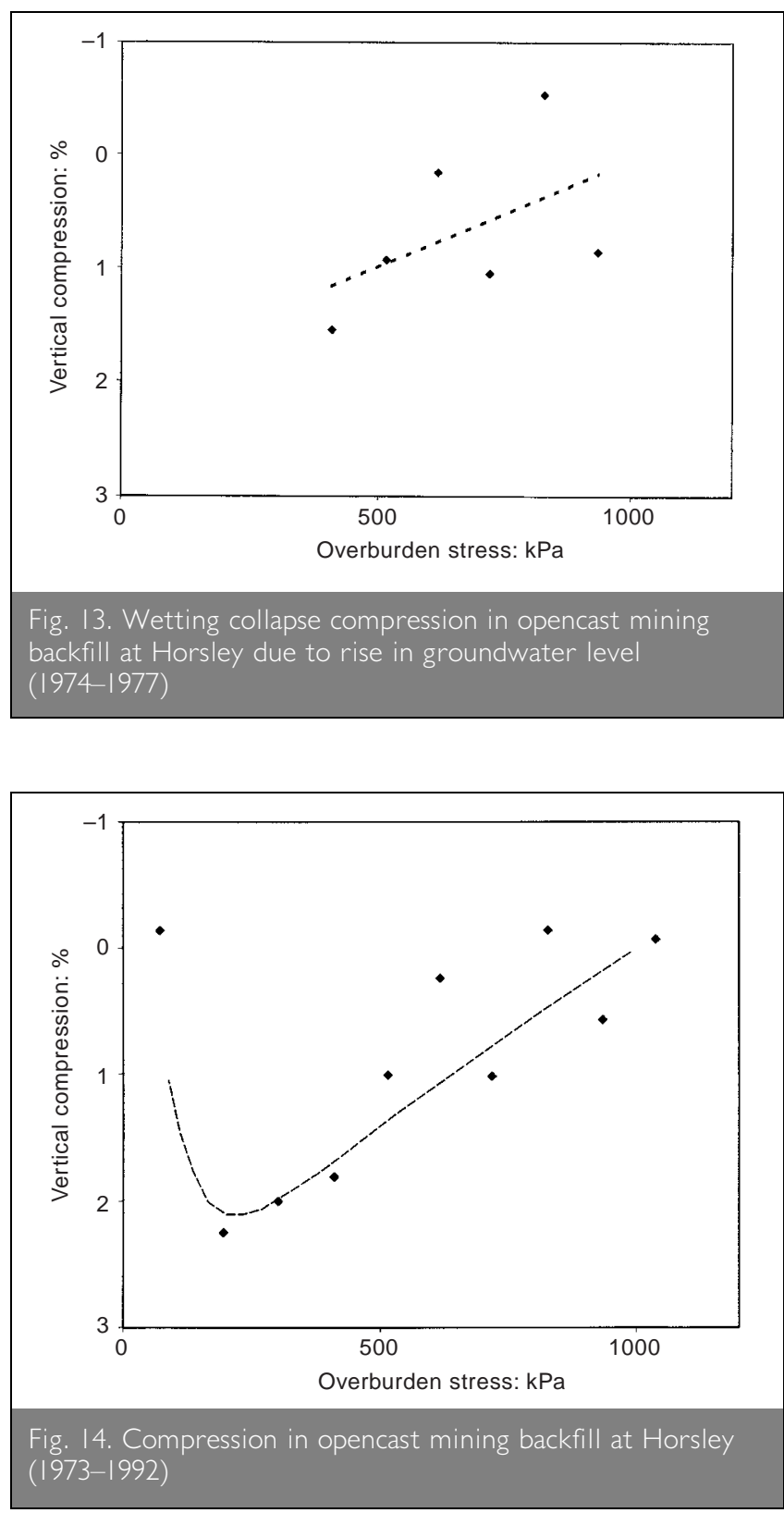
compression can be attributed to wetting. A maximum compression of more than $2 \%$ occurred at an overburden stress of $200 \mathrm{kPa}$.

At the Tinsley opencast site described by the authors there was an engineered fill and the collapse potential may be significantly smaller than that monitored on the non-engineered fill at Horsley. The data from Tinsley presented by the authors relate only to surface settlement with no information about the depth at which compression occurred. The absence of field data relating wetting compression to overburden stress means that the validity of the authors' conclusions derived from laboratory testing concerning the linear increase of wetting compression with increasing vertical stress cannot be confirmed for the field behaviour.

The claim (paragraph 23) that the laboratory linear relationship shown in Fig. 5 refutes the findings of the field investigations described in References 4 and 5 does not appear to have been substantiated. The differences between the authors' laboratory test results and the monitored field behaviour at Horsley may be related to the differences between the fill material at Horsley and the material used in the authors' laboratory tests, particularly with regard to particle size distribution. The authors' method of forming laboratory samples by breaking down large blocks of mudstone to a maximum particle size of $20 \mathrm{~mm}$ using a vibrating hammer (paragraph 11) produced fill material with the grading shown in Fig. 2 which contained much less fine material than was present in the opencast backfill at Horsley. Fig. 1 relates to BRE tests on opencast mudstone backfill from another site which had 60\% fines (silt and clay size particles) whereas the authors' laboratory samples apparently had virtually zero fines.

The authors' predictive model is based on a relationship between collapse compression and overburden stress and compaction air voids respectively. The authors have correctly recognised that predicted settlements are significantly more sensitive to variations in compaction air voids than to variations in overburden stress (paragraph 44). However, Fig. 1 shows that at a given overburden stress, there is no reason to expect a unique relationship between wetting collapse and percentage air voids.

\section{Authors' reply}

Charles and Skinner correctly point out that the compression at depth was not measured at the Tinsley opencast coal site. The authors therefore agree that the relationship found in laboratory tests between wetting collapse and overburden stress (Fig. 5) has not been corroborated by field evidence. They would, however, reiterate (paragraphs 3 and 4) that there is contradictory evidence about whether or not such a relationship does, or should, exist, and the results of their laboratory tests provide evidence that it does. However, in claiming that the laboratory test results 'refute the findings' from Horsley and other studies, the authors acknowledge that they have inadvertently overstated their conclusion.

Two things that were demonstrated in the work reported by the authors were that:

(a) in the laboratory tests, the magnitude of wetting collapse was much more sensitive to small variations in the percentage air voids than to changes in overburden stress

(b) the compaction results from Tinsley showed that even in a 'carefully' engineered backfill, air voids will vary greatly (between 0-24\%) from layer to layer within the fill.

Therefore, it is the basis of the authors' argument that, given the above facts, it is impractical to draw any conclusions relating wetting collapse to overburden stress from field results. This may be one of the reasons why numerous authors have not yet been able to establish a clear, unique relationship when analysing the results of field studies. Other contributory factors probably relate to the spatial variability and uncertainties in the material and physical properties in the field. Only in the carefully controlled material selection, compaction and testing conditions of the laboratory can a relationship be established with any certainty. 